\title{
The good, the bad, and the ugly: Contemporary options for biventricular support
}

\author{
David L. Joyce, MD
}

From the Department of Cardiovascular Surgery, Mayo Clinic, Rochester, Minn

Disclosures: Author has nothing to disclose with regard to commercial support.

Received for publication Oct 22, 2015; accepted for publication Oct 22, 2015; available ahead of print Nov 19. 2015 .

Address for reprints: David L. Joyce, MD, Department of Cardiovascular Surgery, Mayo Clinic, 200 First St, SW, Rochester, Minn (E-mail: joyce.david1@ mayo.edu).

J Thorac Cardiovasc Surg 2016;151:536-7

0022-5223/\$36.00

Copyright (C) 2016 by The American Association for Thoracic Surgery

http://dx.doi.org/10.1016/j.jtcvs.2015.10.085

Implantation of a long-term mechanical circulatory support device occurred for the first time in 1982, with the implantation of a total artificial heart (TAH) in Barney Clark, MD. ${ }^{1}$ Now, more than 3 decades later, the field has evolved substantially, having gone through several paradigm shifts along the way. Left ventricular assist device (LVAD) strategies have largely supplanted cardiac replacement, with the goals of therapy evolving to include "bridge to transplant" and "destination therapy." Although LVAD technology has transitioned, from pulsatile, to axial and centrifugal flow strategies, the currently approved, long-term biventricular support options bear a striking resemblance to the TAH that was implanted in Dr Clark.

Copeland and colleagues ${ }^{2}$ present a contemporary analysis of biventricular support in their analysis of 408 patients reported to the United Network for Organ Sharing database. In this bridge-to-transplant population, biventricular support was associated with worsening 1- and 6-month survival rates ( $83 \%$ and $68 \%$, respectively), compared with LVAD support ( $98 \%$ and $93 \%$, respectively). Relative to the TAH outcomes presented in 2004 (1-year survival of $70 \%),{ }^{2}$ these data suggest that little progress has been made in the treatment of biventricular failure.

In contrast, LVAD outcomes have improved from the early HeartMate II (Thoratec Corporation, Pleasanton, Calif) experience; 6-month survival was reported ${ }^{3}$ at $75 \%$ to $91 \%$ in the postapproval data, ${ }^{4}$ and at $92.7 \%$ (including all devices) in the current study. In addition, the authors compared various strategies for managing the failing right ventricle. Perhaps as a result of the relatively small sample size, statistical differences were not seen among the various approaches described. As the authors suggest, device selection for biventricular support is often driven by patient characteristics and center experience, rather than by perceived outcomes or anticipated waiting times. From this important analysis, a few general observations are worth noting.

\section{THE GOOD}

In selected patients, the Syncardia TAH (SynCardia Systems, Inc, Tucson, Ariz) offers a reasonable strategy for

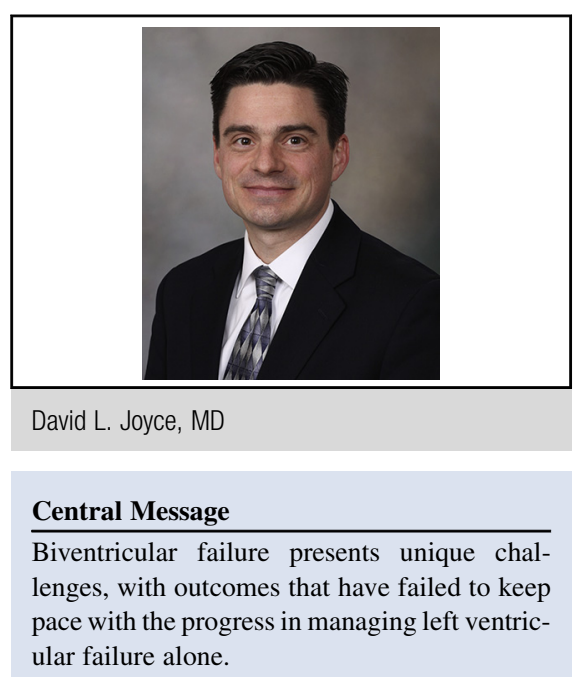

See Article page 530.

bridge to transplant, accounting for the majority of implants (172 patients) in the present series. However, size constraints have limited the widespread adoption of this technology, with few centers implanting $>5$ of these devices annually. Perhaps the availability of the 50-cc design will expand the pool of eligible patients.

\section{THE BAD}

Despite the fact that patients who underwent right ventricular assist device insertion after LVAD insertion were excluded, many of the 110 patients that were managed with a CentriMag (Thoratec) right ventricular assist device were likely cases in which the intended approach was to use an LVAD only, with subsequent failure to wean from cardiopulmonary bypass. This strategy, in comparison with planned biventricular support up front, has been shown to decrease survival to discharge.

\section{THE UGLY}

Historically, implantation of a Thoratec percutaneous ventricular assist device has been associated with a $60 \%$ survival to transplant. ${ }^{6}$ As device technology becomes increasingly miniaturized, paracorporeal approaches likely will be reserved for patients with a low body surface area. The increased mortality rate described in patients who have a higher body surface area (4th quartile) further supports this assertion.

Despite the fact that only 28 patients in this series were implanted with a continuous flow biventricular support 


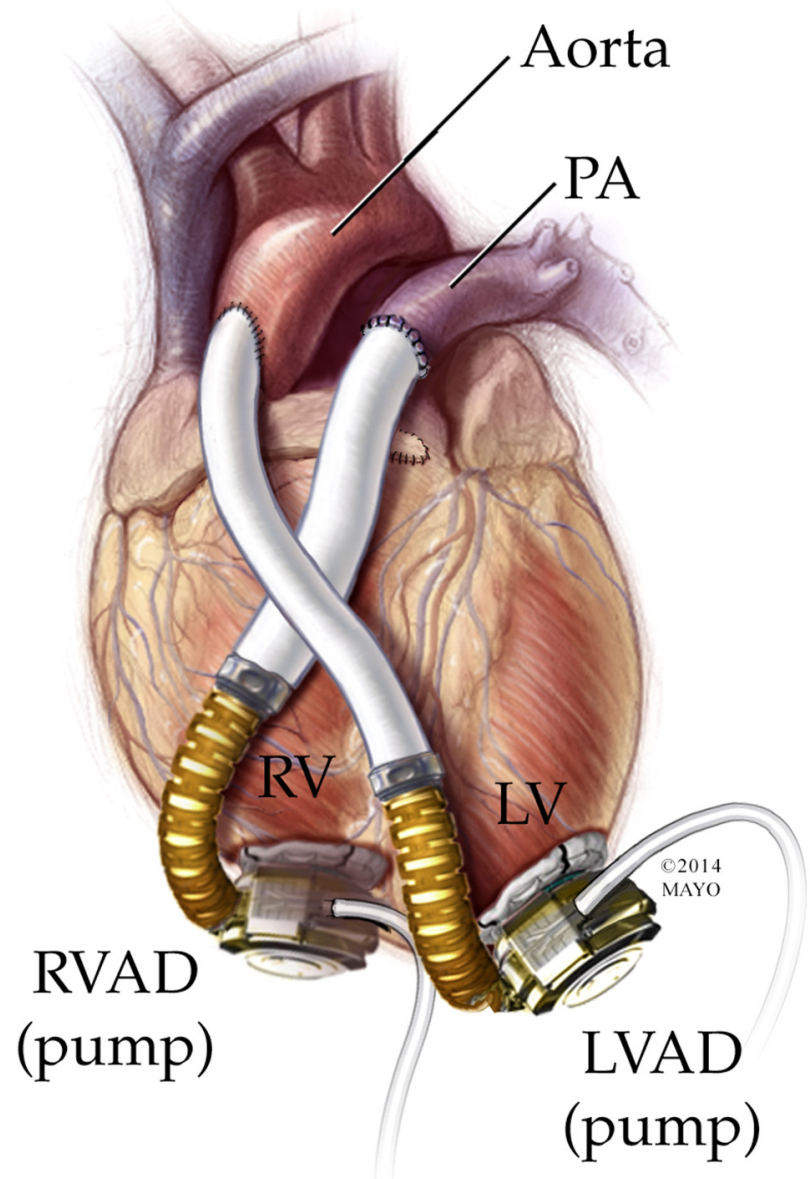

FIGURE 1. Using the HeartWare device for long-term right-sided support can be accomplished by anchoring the inflow cannula to the tricuspid annulus, through the free wall of the right ventricle. The PA is amputated with end-to-end anastomosis of the RVAD outflow graft to the distal PA, and drainage of the proximal PA to the right atrial appendage. $P A$, Pulmonary artery; $R V$, right ventricle; $L V$, left ventricle; $R V A D$, right ventricular assist device; $L V A D$, left ventricular assist device.

strategy, this option seems to be gaining traction in the medical literature. ${ }^{7,8}$ Amidst the operative challenges associated with this type of procedure, our group at the Mayo Clinic has recently described a technique whereby the HeartWare (HeartWare International, Inc, Framingham, Mass) device can be secured to the tricuspid annulus via the right ventricular free wall, connecting the outflow graft to the pulmonary artery with an end-to-end anastomosis and draining the remnant of the right ventricle by a connection to the right atrial appendage (Figure 1).

\section{CONCLUSIONS}

The data presented here have important implications for the field. Biventricular failure presents a formidable challenge to improving outcomes, compared with left-sided support strategies. In the absence of a large patient population to drive demand for major technologic advances, consideration should be given to revising the organ prioritization scheme, which fails to account for the differences in outcomes described here. In the absence of a rightventricle-specific assist device platform, optimizing use of the existing technology may represent the best approach to managing the difficulties associated with treating these patients. Toward that end, this work represents an important step in understanding the complexities and limitations of biventricular support in the current era.

\section{References}

1. Joyce LD, DeVries WC, Hastings WL, Olsen DB, Jarvik RK, Kolff WJ, et al Response of the human body to the first permanent implant of the Jarvik-7 Total Artificial Heart. Trans Am Soc Artif Intern Organs. 1983;29:81-7.

2. Copeland JG, Smith RG, Arabia FA, Nolan PE, Sethi GK, Tsau PH, et al; CardioWest Total Artificial Heart Investigators. Cardiac replacement with a total artificial heart as a bridge to transplantation. New Engl J Med. 2004;351:859-67.

3. Miller LW, Pagani FD, Russell SD, John R, Boyle AJ, Aaronson KD, et al; HeartMate II Clinical Investigators. Use of a continuous-flow device in patients awaiting heart transplantation. New Engl J Med. 2007;357:885-96.

4. Starling RC, Naka Y, Boyle AJ, Gonzalez-Stawinski G, John R, Jorde U, et al. Results of the post-U.S. Food and Drug Administration-approval study with a continuous flow left ventricular assist device as a bridge to heart transplantation: a prospective study using the INTERMACS (Interagency Registry for Mechanically Assisted Circulatory Support). J Am Coll Cardiol. 2011;57:1890-8.

5. Fitzpatrick JR III, Frederick JR, Hiesinger W, Hsu VM, McCormick RC Kozin ED, et al. Early planned institution of biventricular mechanical circulatory support results in improved outcomes compared with delayed conversion of a left ventricular assist device to a biventricular assist device. J Thorac Cardiovasc Surg. 2009; 137:971-7.

6. Farrar DJ. The Thoratec ventricular assist device: a paracorporeal pump for treating acute and chronic heart failure. Semin Thorac Cardiovasc Surg. 2000;12: 243-50.

7. Loforte A, Monica PL, Montalto A, Musumeci F. HeartWare third-generation implantable continuous flow pump as biventricular support: mid-term follow-up. Interact Cardiovasc Thorac Surg. 2011;12:458-60.

8. Krabatsch T, Potapov E, Stepanenko A, Schweiger M, Kukucka M, Huebler M et al. Biventricular circulatory support with two miniaturized implantable assist devices. Circulation. 2011;124(11 Suppl):S179-86. 